\title{
Uma Alternativa para o Fortalecimento da Inovação nas Áreas Farmacêutica e de Biotecnologia no Brasil
}

Dissertação apresentada ao Programa de Pós Graduação Interunidades em Biotecnologia USP/ Instituto Butantan/IPT, para obtenção do Título de Mestre em Biotecnologia

São Paulo

2009 


\section{Uma Alternativa para o Fortalecimento da Inovação nas Áreas Farmacêutica e de Biotecnologia no Brasil}

FERNANDO CASTRO SILVA CAVALCANTE

Dissertação apresentada ao Programa de Pós Graduação Interunidades em Biotecnologia USP/ Instituto Butantan/IPT, para obtenção do Título de Mestre em Biotecnologia

Área de Concentração: Biotecnologia

Orientadora: Dra. Beatriz Lieblich Fernandes

São Paulo

2009 
Cavalcante, Fernando Castro Silva.

Uma alternativa para o fortalecimento da inovação nas áreas farmacêutica e de biotecnologia no Brasil / Fernando Castro Silva Cavalcante. -- São Paulo, 2009.

Orientador: Beatriz Lieblich Fernandes.

Dissertação (Mestrado) - Universidade de São Paulo. Instituto de Ciências Biomédicas. Programa de Pós-Graduação Interunidades em Biotecnologia USP/IPT/Instituto Butantan. Área de concentração: Biotecnologia. Linha de pesquisa: Busca de opções no arcabouço legal brasileiro para o fomento da inovação farmacêutica e tecnológica.

Versão do título para o inglês: An alternative to reinforce the innovation in the pharmaceutical and biotechnological fields in Brazil.

Descritores: 1. Biotecnologia 2. Inovação 3. Farmacêutica 4. Pesquisador 5. Aprimoramento I. Fernandes, Beatriz Lieblich II. Universidade de São Paulo. Instituto de Ciências Biomédicas. Programa de Pos-Graduação em Biotecnologia. III. Título. 


\section{UNIVERSIDADE DE SÃO PAULO \\ Programa de Pós-Graduação Interunidades em Biotecnologia}

Universidade de São Paulo, Instituto Butantan, Instituto de Pesquisas Tecnológicas

Candidato(a): $\quad$ Fernando Castro Silva Cavalcante.

Título da Dissertação: $\quad$ Uma alternativa para o fortalecimento da inovação nas áreas farmacêutica e de biotecnologia no Brasil.

Orientador(a): $\quad$ Beatriz Lieblich Fernandes.

A Comissão Julgadora dos trabalhos de Defesa da Dissertação de Mestrado, em sessão pública realizada a ....................................,
( ) Aprovado(a)
( ) Reprovado(a)

Examinador(a): $\quad$ Assinatura:

Nome:

Instituição:

Examinador(a): Assinatura:

Nome:

Instituição:

Presidente: Assinatura:

Nome:

Instituição: 


\section{AGRADECIMENTOS}

Ao Professor Antonio Carlos Martins de Camargo, por ter me introduzido no universo da Biotecnologia e por seus preciosos ensinamentos.

À minha orientadora, Dra. Beatriz Lieblich Fernandes, pela paciência e pelo balizamento, cruciais para a elaboração do trabalho.

À minha esposa Patrícia, pela compreensão, paciência e apoio.

À Anamaria Baptista Villela Leme, pela ajuda na revisão e formatação do trabalho. 


\section{RESUMO}

CAVALCANTE, F. C. S. Uma alternativa para o fortalecimento da inovação nas áreas farmacêutica e de biotecnologia no Brasil. 36 f. Dissertação (Mestrado em Biotecnologia) Instituto de Ciências Biomédicas, Universidade de São Paulo, São Paulo, 2009.

O presente trabalho apresenta uma alternativa para despertar nos principais players do setor da inovação farmacêutica e biotecnológica um interesse maior em utilizar os resultados das invenções brasileiras de empresas e instituições de pesquisa na produção de novos medicamentos. Considerando o atraso brasileiro em relação aos processos de inovação que derivam do conhecimento cientifico e as inúmeras peculiaridades dessas inovações nas áreas farmacêuticas e biotecnológicas, apresentamos algumas sugestões de incremento no arcabouço jurídico nacional com base em estruturas legais e, também, em parte da legislação americana como paradigma para algumas mudanças. Nesse sentido, sugerimos a criação de sociedades de propósito específico entre os setores público e privado para o desenvolvimento da inovação, o que permitiria que questões estratégicas, como a co-titularidade das patentes, fossem dirimidas em acordos societários (“quotistas” ou “acionistas”). Além disso, recomendamos a constituição de um núcleo de inovação tecnológica em institutos de pesquisa como no "Instituto Butantan” para usufruir dos benefícios da lei de inovação, principalmente em relação ao licenciamento de patentes e, nos moldes do Bayh Dole Act em vigor nos Estados Unidos, sugerimos que o setor público, ao licenciar as patentes, privilegie as empresas nacionais de pequeno porte.

Palavras-chave: Biotecnologia. Inovação Biotecnológica. Inovação Farmacêutica. Licenciamento de patentes. 


\begin{abstract}
CAVALCANTE, F. C. S. An alternative to reinforce the innovation in the pharmaceutical and biotechnological fields in Brazil. $36 \mathrm{f}$. Dissertação (Mestrado em Biotecnologia) - Instituto de Ciências Biomédicas, Universidade de São Paulo, São Paulo, 2009.

The present work suggests alternatives in the pharma and biotechnology innovation areas to use the results of Brazilian inventions obtained in research institutes and biotechnology companies for the production of novel drugs. We present some suggestions to improve the Brazilian legal system based on legal structures and using examples of the American legal system as a reference. Thus, we suggested setting up "specific purposes companies” between the public and private sector to develop innovation, which would allow solving strategic questions, such as patent co-ownership, through corporate agreements ("quotaholders” or "shareholders"). In addition, we recommend the establishment of a technology innovation office in researches institutes, such as "Instituto Butantan" to allow it to be able to take advantages offered by the Brazilian innovation law and, along the lines of the Bayh Dole Act, duly in force in United States, we suggested that the public sector, when licensing its patents, grant privileges to small national companies.
\end{abstract}

Key-Words: Biotechnology. Biotechnology Innovation. Pharmaceutical Innovation. Patents Licensing. 


\section{SUMÁRIO}

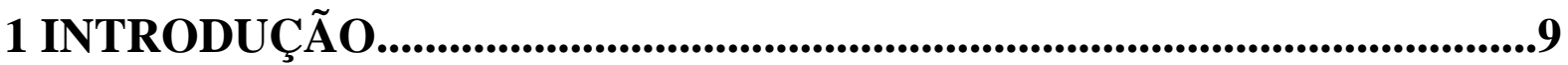

1.1 Alguns comentários à evolução da indústria farmacêutica nacional .....10

1.2 Modelo CAT de inovação (CAT-CEPID, 2007) ...........................................13

1.3 A importância do Bayh-Dole Act nos EUA ......................................................14

1.4 Questões envolvendo titularidade de patentes ..............................................16

1.5 Outros entraves ao crescimento da inovação nesses segmentos ..............17

1.6 Diagnósticos relacionados à inovação brasileira ...........................................18

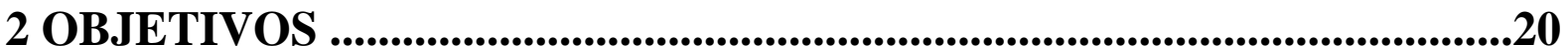

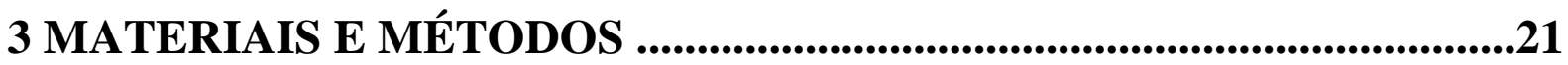

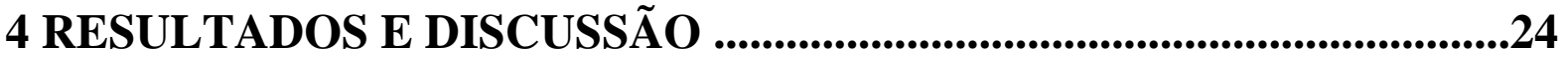

4.1 Sociedades de Propósito Específico (SPE) .....................................................26

4.2 Instituições Científicas e Tecnológicas (ICT) .............................................28

4.3 Licenciamento de Invenções de Propriedade do Estado ...........................29

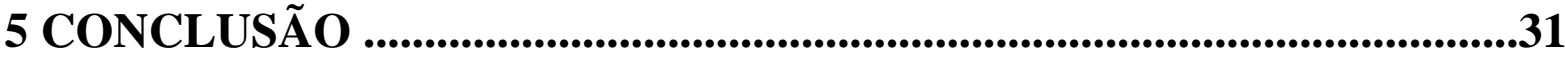

REFERÊNCIAS BIBLIOGRÁFICAS .........................................................32 


\section{INTRODUÇÃO}

A riqueza dos recursos naturais brasileiros, aliado ao fato de nossa biodiversidade ser uma excelente fonte de material de pesquisas nas áreas farmacêutica e da biotecnologia, levou a um crescimento considerável das publicações científicas nessas áreas nos últimos anos. Não obstante, a proteção do conhecimento gerado não vinha sendo feita de maneira que pudesse agregar valor e assim contribuir para a riqueza do país.

Com efeito, para comprovar essa afirmação, basta mencionar uma comparação feita entre os triênios 2002-04 e 2005-07, que mostrou que a produção cientifica brasileira cresceu 33\%, chegando ao $15^{\circ}$ lugar do ranking mundial. Na China o crescimento foi de $73 \%$ ( $2^{\circ}$ lugar no ranking). O número de patentes concedidas ao Brasil e à China pela agencia norte-americana de patentes e marcas, o "Escritório Americano de Patentes - USPTO”, no mesmo período mostrou que o país asiático obteve o registro de 2775 patentes enquanto o Brasil registrou apenas 288 patentes ${ }^{1}$.

A escassez de patentes brasileiras nas áreas farmacêutica e de biotecnologia deve-se a vários fatores de naturezas diversas, que, entrelaçados, não permitem o desenvolvimento da inovação nesses segmentos de forma proporcional a sua importância e aos subsídios encontrados em nosso País.

A questão cultural, que se mostra na distância entre a academia e o empresariado, na falta do desenvolvimento de pesquisa dentro das empresas e no pensamento ainda vigente da academia que não quer "mercantilizar" a pesquisa, vem sendo modificada lentamente. Como exemplo, mencionamos a realização de vários workshops realizados no País com a participação de representantes de ambas as partes, citando, dentre vários, o "Lei da Inovação: A nova realidade das Instituições Científicas Tecnológicas (ICT’s) com a lei da inovação e a política industrial, tecnológica e de comércio exterior (PITCE)”, ocorrido em Campina Grande, Paraíba, no mês de Junho de 2006. Um dos objetivos desse workshop foi o de disseminar a lei de inovação dimensionando os impactos dos instrumentos de inovação junto às ICTs e no seu relacionamento com a iniciativa privada. Dentre os palestrantes, participaram representantes de universidades brasileiras, da confederação nacional das indústrias e do SEBRAE.

\footnotetext{
${ }^{1}$ CAPES, 2007.
} 
A falta de conhecimento em relação à melhor forma de proteção à propriedade intelectual faz com que, muitas vezes, o desencontro entre o desejo dos vários elos da cadeia da inovação não resulte em invenções dignas de proteção, resultando em publicações, e assim inviabilizando sua proteção por patentes ou chegando ao conhecimento de terceiros, os quais poderão usufruir suas benesses se nenhuma medida for tomada.

\subsection{Alguns comentários à evolução da indústria farmacêutica nacional}

A partir do ano de final do século XIX começaram a ser criados institutos de pesquisa no País para o suprimento de soros e vacinas, como o “Butantan”, o “Manguinhos” e o "Vital Brasil”. No ano de 1920 havia 186 laboratórios e, a partir desse ano, as indústrias farmacêuticas européias passaram a ingressar no Brasil. Como conseqüência desse ingresso, passaram a produzir no País embalagens específicas para os medicamentos, como ampolas e vidro neutro (CAMARGO; SCIVOLETTO; D’AVILA, 2004).

Uma das vantagens desse crescimento - até o ano de 1947 - é que o Brasil passou a consumir 90\% dos produtos aqui fabricados e atingiu auto-suficiência em alguns, como os imunobiológicos. Nesse mesmo ano, havia no País 611 laboratórios.

Não obstante, é fato que as empresas estrangeiras que aqui se instalaram acabaram provocando a "desnacionalização” de nossa indústria, vez que tanto seu capital como sua direção eram estrangeiros e seus lucros eram remetidos ao exterior. Além disso, as fórmulas dos remédios vinham prontas da matriz, o que significava o pagamento, pela filial brasileira à matriz, dos royalties pela venda do produto (aí incluindo o custo da remessa, o que encarecia ainda mais o medicamento) (MIRANDA, 1963)

A partir daquele ano a indústria nacional entrou em declínio (CAMARGO; SCIVOLETTO; D’AVILA, 2004). O consumo nacional de medicamentos aumentou 10 vezes e, no ano de 1961, passamos a consumir $4 \%$ de todos os medicamentos comercializados no mundo. Nesse mesmo ano, o Governo constituiu uma Comissão de Inquérito para apurar as causas da desnacionalização da indústria farmacêutica (MIRANDA, 1963), que, dentre as sugestões principais para reverter o quadro (como, por exemplo, financiamentos especiais e redução de direitos aduaneiros e de impostos para a aquisição de equipamentos das indústrias “genuinamente nacionais”) e conclusões a que chegou, mencionamos a cartelização da indústria química (produtora das matérias primas para 
as indústrias farmacêuticas), que reforça essa posição através de patentes, impedindo que países subdesenvolvidos ficassem independentes das empresas estrangeiras. Por tal motivo, recomendouse a não concessão de patentes a produtos destinados ao uso farmacêutico (o que já não era permitido pela legislação da época). Entretanto, o Código da Propriedade Industrial então vigente ${ }^{2}$ permitia a concessão de patentes para processos e técnicas (art.8º, par. Único, “a”), o que, automaticamente, garantia o privilégio para o produto. Apesar disso, para não ferir compromissos internacionais assumidos pelo Brasil, essa sugestão não foi aprovada.

Outro aspecto importante é que a participação universitária na inovação farmacêutica foi bastante reduzida nos anos 60, quando a maioria das universidades estaduais e federais foi criada (CAMARGO; SCIVOLETTO; D’AVILA, 2004). Todavia, naquele período, o Governo não se preocupou em manter e ampliar a competitividade da indústria local, o que incluiria a participação mais ativa das universidades na formação de pessoal qualificado.

Já nos anos 70, passou a vigorar um novo “Código da Propriedade Industrial” (lei 5772/71), que também não permitia o patenteamento de produtos farmacêuticos. Levando em consideração que os custos para que uma grande idéia seja convertida em um fármaco patenteável (estudos feitos na Universidade de Tufts nos Estados Unidos, estimaram em mais de US\$880 milhões), incluindo aí o tempo de maturação do fármaco - que pode ser superior a 10 anos - e os custos dos riscos, que chegam a 80\% (CAMARGO; SCIVOLETTO; D’AVILA, Ibid), podemos afirmar que estava montado o cenário perfeito para que não houvesse nenhum interesse em promover a inovação radical (desenvolvimento de um novo fármaco) no segmento. Isso fez com que a indústria farmacêutica produzisse apenas inovações incrementais (ou seja, a implementação de alterações em compostos pré-existentes), o que afetou, de forma negativa, a criação de novos conhecimentos.

\footnotetext{
2 “Art. $8^{\circ}$ Não são privilegiáveis:

$1^{\circ}$ ) As invenções de finalidades exclusivamente contrárias às leis, a moral, à saúde e a segurança públicas;

$2^{\circ}$ ) as invenções que tiverem por objeto substâncias ou produtos alimentícios e medicamentos de qualquer gênero;

$3^{\circ}$ ) as invenções que tiverem por objeto matérias ou substâncias obtidas por meios ou processos químicos;

$4^{\circ}$ ) as concepções puramente teóricas;

$5^{\circ}$ ) a justaposição de órgãos conhecidos, a simples mudança de forma, proporções, dimensões ou de materiais, salvo se dai resultar, no conjunto, um efeito técnico imprevisto;

$6^{\circ}$ ) os sistemas de escrituração comercial, de cálculos onde combinação de finanças ou de créditos, bem como os planos de sorteio, especulação ou propaganda.

Parágrafo único. Na proibição constante dos números $2^{\circ}$ e $3^{\circ}$, deste artigo, não se incluem e em conseqüência podem ser privilegiados:
}

a) os processos novos destinados à fabricação das substâncias, produtos ou matérias nelas mencionados” 
Apesar disso, as indústrias farmacêuticas brasileiras mantém, ainda hoje, essa mentalidade de que as inovações incrementais são mais proveitosas para o segmento. No recente "II Encontro Nacional de Inovação em Fármacos e Medicamentos”, o diretor de pesquisa, desenvolvimento e inovação, Márcio Falci, defende as cópias criativas no setor por achar que a ação cumulativa de várias invenções incrementais produz, muitas vezes, mais transformação e mais impacto econômico do que uma inovação radical (PROTEC, 2008).

No segmento farmacêutico e de biotecnologia, a inovação incremental pode ser diretamente desenvolvida pelas empresas do setor, dispensando, na maioria dos casos, a pesquisa especializada que, no Brasil, é desenvolvida principalmente nas universidades e institutos de pesquisa. Se por um lado a indústria brasileira opta por prescindir desse conhecimento, por outro lado este, ao invés de ser protegido - atualmente, é sabido que o Brasil permite a obtenção de patentes de produtos farmacêuticos - acaba sendo objeto de publicações acadêmicas ou científicas, inviabilizando a proteção posterior por ter deixado de ser uma novidade, uma das exigências legais para a concessão de patentes.

Esse entendimento é corroborado por especialistas do setor. Antonio Carlos Martins de Camargo, coordenador do CAT/CEPID, neste mesmo evento destaca o aspecto de que a inovação farmacêutica não se faz sem a participação da indústria. Como a indústria nacional alega não ter dinheiro nem competência para desenvolver inovações, os pesquisadores continuarão divulgando suas descobertas através de papers.

Um passo importante na direção de aproximar o segmento acadêmico do empresarial, isto é, aproximar a pesquisa da inovação, foi dado pela Fundação de Amparo à Pesquisa do Estado de São Paulo (FAPESP) em 2001 quando criou os Centros de Pesquisa, Inovação e Difusão (CEPIDs). Um desses centros, o Centro de Toxinologia Aplicada (CAT) está inserido no segmento farmacêutico/biotecnológico, já que sua missão científico-tecnológica é a de construir um sistema capaz de transformar os resultados das pesquisas biomédicas que utilizam toxinas da biodiversidade brasileira como ponto de partida, em produtos farmacêuticos e/ou biotecnológicos em parceria com a indústria farmacêutica.

Analisando a história do CAT - que nos inspirou a elaborar esta tese - verifica-se que, por melhor que sejam a intenção, a estrutura e os recursos humanos engajados nessa causa, se certas 
correções não forem implementadas no modelo vigente do aproveitamento das inovações, projetos em fase avançada não vão prosperar.

A experiência do CAT mostrou dois sérios problemas: entraves legais que serão objeto dessa dissertação, e entraves resultantes da necessidade de sinergia entre o governo, a academia e a indústria. Exemplos de outros países podem ser citados mostrando a importância de ajustes nessas áreas. Um dos mais dramáticos aconteceu na Irlanda, onde oito das dez maiores companhias farmacêuticas do mundo estão hoje operando. Uma decisão de governo criou as condições necessárias para que houvesse investimentos maciços nas áreas de inovação do país. Isto resultou na criação de 44.000 empregos e uma exportação equivalente de 40 bilhões de euros no setor farmacêutico e biotecnológico. Foram aprovadas pelo FDA trinta e duas plantas de manufatura de produtos, entre os quais estão oito dos dez produtos farmacêuticos mais vendidos do mundo (ROBEN, 2008).

\subsection{Modelo CAT de inovação (CAT-CEPID, 2007)}

A atuação do CAT é focada na pesquisa de toxinas animais e microbianas, podendo ser considerado uma referência brasileira no que se refere à qualidade da pesquisa nas áreas farmacêutica e biotecnológica desde o ano de sua criação em 2001. A constituição do CAT foi motivada por uma forte determinação da FAPESP e de seu coordenador de construir um sistema que pudesse permitir a transformação dos resultados de pesquisas naquelas áreas - utilizando-se da biodiversidade brasileira - em produtos.

A história do CAT mostra que houve fases distintas desde sua criação, tanto no plano de pesquisa como no da inovação. A primeira fase, compreendida entre os anos 2001 e 2004, concentrou-se em duas atividades principais, quais sejam, o estabelecimento da infra-estrutura para caracterização molecular e farmacológica de toxinas que apresentassem potencial terapêutico e a identificação e suporte a projetos que tivessem um bom potencial para gerar inovações na área farmacêutica. Na área da inovação, muito incipiente na época, foram ministrados vários cursos, como, por exemplo, Pharmaceutical and Biotechnology Patent Law in the United States em 2001, dado pelo advogado Richard H. Kjeldgaard do escritório Collier Shannon Scott de Washington DC, EUA (KJELDGAARD, 2001), referentes à propriedade intelectual e, organizados workshops focados em temas referentes à inovação farmacêutica. Na segunda fase (2004-2007), aumentaram 
os esforços para patentear os resultados das invenções, em parceria com indústrias farmacêuticas nacionais. A fase atual, iniciada em 2008, tem por objetivo agregar valor às moléculas descobertas, utilizando a infra-estrutura do CAT e seus laboratórios associados, infra-estrutura essa que possibilita ao CAT estabelecer um núcleo de desenvolvimento inicial de drogas e prestar serviços às indústrias farmacêuticas em várias etapas do desenvolvimento inicial de medicamentos.

Nos últimos seis anos o Centro de Toxinologia Aplicada depositou 13 patentes, 10 das quais em parceria com indústrias farmacêuticas brasileiras que receberam o licenciamento para desenvolver os produtos. Com tal compromisso, essas indústrias ficaram credenciadas a participar da propriedade intelectual de cada uma delas, além da FAPESP e do pesquisador principal. O contrato de colaboração cientifica firmado entre as indústrias e a FAPESP em 2004, para dar base legal a esse modelo, entretanto, despertou questionamentos legais que serão objetos dessa dissertação.

A parceria do CAT com indústrias farmacêuticas brasileiras (Biolab-Sanus, União Química, Biosintética/Aché) se deu desde o início de suas atividades, obedecendo ao Termo de Outorga da FAPESP para os CEPIDs. Assim, além do fomento da FAPESP para o bom andamento de suas pesquisas, o CAT buscou investimentos para seus trabalhos junto à iniciativa privada, mais especificamente as indústrias farmacêuticas nacionais. Não obstante tais esforços, essa parceria foi descontinuada principalmente em virtude de questões envolvendo a titularidade dos direitos de propriedade intelectual de invenções geradas por empregados de instituições públicas (inventores/pesquisadores).

Resumindo, o objetivo do modelo CAT de inovação é o de proteger os resultados iniciais de uma invenção (patente genérica), licenciando não a patente completa, mas apenas aplicações específicas, após a bem sucedida conclusão dos estágios iniciais de desenvolvimento, suportados por recursos não reembolsáveis (como, por exemplo, do programa PIPE-FAPESP).

\subsection{A importância do Bayh-Dole Act nos EUA}

Um marco importante no aproveitamento de inovações geradas em universidades públicas ou particulares, oriundas de pesquisas financiadas com dinheiro público foi o Bayh-Dole Act, promulgado nos Estados Unidos em 1980. Dentre os aspectos mais importantes desse marco legal, 
destacam-se a obrigatoriedade da universidade de optar por manter a titularidade da invenção, conceder ao Governo americano uma licença mundial não exclusiva, não transferível e irrevogável, e também o fato de que os produtos das empresas licenciadas terem que ser manufaturados, salvo quando não for possível comprovar a capacidade técnica das mesmas, por indústrias americanas.

O Bayh-Dole Act facilitou o patenteamento e o licenciamento em pelo menos duas formas (MOWERY et al, [ca.2003]): (i) substituiu a chamada rede de "Acordos Institucionais de Patentes" que foram negociados entre universidades e "agências federais" por uma política uniforme e (ii) as disposições do Bayh-Dole expressam o apoio do Congresso para a negociação de licenças exclusivas entre universidades e indústrias em relação aos resultados da pesquisa feita com o dinheiro público (COUNCIL ON GOVERNMENTAL RELATIONS, 1999).

Naquele ano, o Governo daquele país era titular de aproximadamente 28.000 patentes. Apenas 5\% desse total eram licenciados para a indústria devido ao fato de haver restrições ao licenciamento de novas tecnologias e relutância das agências em permitir a titularidade das invenções por universidades. Além disso, o Governo não renunciaria à titularidade de suas invenções em prol da organização inventora, com raras exceções. Normalmente, o Governo americano mantinha a titularidade e concedia licenças “não exclusivas” aos interessados.

Como conseqüência desta "reserva de mercado", as empresas não investiam em novos produtos. Assim, o Governo não atraía investimentos privados e os contribuintes não se beneficiavam de um verdadeiro desenvolvimento econômico.

Após o Bayh-Dole, aumentou a colaboração entre universidades e empresas. Sua implementação incrementou muito a comercialização de novas tecnologias que impactaram milhões de pessoas nos Estados Unidos, sendo que aproximadamente 70\% das licenças concedidas referemse às ciências da vida, como, por exemplo, inovações na área dos diagnósticos de doenças. A maioria dessas invenções recebeu auxílio financeiro do Governo, sendo importante mencionar, a título exemplificativo, a descoberta da tecnologia do DNA recombinante, o "CITRACAL", que é um suplemento de cálcio e o "TRUSOPT”, colírio oftálmico usado contra glaucoma.

Assim, as instituições acadêmicas americanas começaram a contar com uma forte infraestrutura de apoio para a transferência de tecnologia. Vale mencionar que, no final da década de 90, já se contabilizava: (i) entre 1993 e 1997, aquelas instituições obtiveram mais de 8.000 patentes para tecnologias descobertas por seus pesquisadores, (ii) mais de 2.200 novas empresas foram 
formadas, desde 1980, como conseqüência de licenciamentos de invenções de instituições acadêmicas, sendo que, apenas no ano de 1997, mais de 330 foram fundadas, (iii) aproximadamente US\$30 bilhões da atividade econômica anual, gerando 250.000 empregos, podem ser creditados à comercialização de novas tecnologias oriundas de instituições acadêmicas, (iv) há mais de 1.000 produtos atualmente no mercado que são originados de descobertas licenciadas por universidades (COUNCIL ON GOVERNMENTAL RELATIONS, Ibid).

\subsection{Questões envolvendo titularidade de patentes}

No sistema jurídico brasileiro, é garantido ao autor de uma invenção o direito de obter uma patente, que, após ser concedida, será de sua propriedade no prazo e nas condições estabelecidas em lei. De acordo com a lei 9.729/96, o Instituto Nacional da Propriedade Industrial (INPI) presume que o requerente de um pedido de patente está legitimado a obtê-la. Isso significa que qualquer pessoa que apresentar um pedido dessa natureza, seja pessoa física ou jurídica, nacional ou estrangeira (neste caso se domiciliados em países que conferem reciprocidade de tratamento aos brasileiros) poderá, “aos olhos” do INPI, ser considerado titular do pedido de patente, se esta for concedida. Mas essa presunção é relativa, vez que eventual interessado poderá apresentar uma oposição ao pedido e demonstrar que é o verdadeiro autor da invenção (LOUREIRO, 1999).

Um pedido de patente pode ser requerido em nome próprio, pelos herdeiros ou sucessores do autor, pelo cessionário ou por quem a lei ou o contrato de trabalho ou de prestação de serviços determinar que pertença a titularidade. Tais aspectos deixam claro que o inventor e o titular de uma patente podem não ser as mesmas pessoas. Se a invenção for realizada em conjunto por duas ou mais pessoas, o pedido poderá ser requerido por todas ou qualquer delas, devendo as demais, para efeitos de ressalva de direitos, serem nomeadas e qualificadas no pedido. O inventor poderá requerer a não divulgação de sua nomeação.

Em relação à propriedade da patente (titularidade) a lei prevê que, na hipótese de a invenção para a qual a patente obtida for resultado de um contrato de trabalho cuja execução ocorra no Brasil e que tenha por objeto a pesquisa ou a atividade inventiva, sua titularidade pertencerá ao empregador, sendo devido ao empregado apenas a retribuição pelo trabalho, salvo expressa disposição contratual em contrário. Essa regra é válida, também, para as entidades da Administração Pública. 
Feitos estes comentários sobre a nossa legislação, passamos a tecer alguns sobre a titularidade das patentes que envolvem o CAT, que é um dos "Centros de Pesquisa, Inovação e Difusão - CEPID” criados pela FAPESP como paradigmas da pesquisa científica em suas especialidades.

As regras pertinentes à propriedade intelectual do resultado das invenções desenvolvidas nos CEPIDs - além de normas pertinentes ao auxílio financeiro concedido para a execução das pesquisas - regem-se pelos respectivos “Termos de Outorga e Aceitação de Auxílio” concedidos pelo Conselho Técnico-Administrativo da FAPESP aos outorgados, dentre eles os responsáveis diretos pelos CEPIDs. No caso específico do CAT, a FAPESP outorgou referido termo, de no. 1998/14307-9, ao Dr. Antonio Carlos Martins de Camargo, responsável pelo programa, com validade de 01.10.2000 a 30.09.2005.

De acordo com as “Condições Gerais de Concessão de Benefícios” do referido termo os rendimentos líquidos serão compartilhados na proporção de 1/3 para a FAPESP, 1/3 para os inventores e 1/3 para as instituições onde foi desenvolvido (item XV). Além disso, no caso de cotitularidades das patentes entre a FAPESP e outros, qualquer concessão ou desistência de direitos deverá ser previamente apreciada pelas partes (item XVI).

Assim, de acordo com o referido termo, tem o outorgado o direito à participação não só no quinhão referente aos ganhos econômicos como também na titularidade das patentes das invenções por ele descobertas. Em relação à instituição onde as invenções foram desenvolvidas - que também participa de 1/3 dos ganhos econômicos - no caso o "Instituto Butantan”, onde o CAT está localizado, é importante ressaltar que seu diretor, Dr. Otávio Azevedo Mercadante, através do Ofício “TBD - 128/05” emitido em 31.05.2005 expressa seu apoio ao CAT e concorda com todos os itens do “Termo de Outorga e Aceitação de Auxílio” aqui referido.

\subsection{Outros entraves ao crescimento da inovação nesses segmentos}

Além da questão que pretendemos abordar sobre a co-titularidade de patentes entre pesquisadores públicos e instituições privadas, é importante mencionar que o Estado não consegue facilitar e estimular o desenvolvimento e a proteção de novas descobertas nos segmentos mercadológicos aqui tratados. 
Como exemplo, podemos mencionar o fato de a "Agência Nacional da Vigilância Sanitária” (ANVISA), por força da Lei da Propriedade Industrial (art.227-C) ter a obrigação de anuir previamente para que novas patentes farmacêuticas sejam concedidas no Brasil. A concessão (pelo Estado) de cartas patentes, dá a seu(s) titular(es) a exclusividade de dispor das mesmas por um determinado período de tempo. Por serem "bens móveis”, os direitos sobre as patentes são patrimoniais, o que significa dizer que poderão ser licenciadas e vendidas (cedidas) sendo que, para sua concessão, deverão ser obrigatoriamente observados os seguintes requisitos ditados pela mesma lei de propriedade industrial, quais sejam, (i) novidade, (ii) atividade inventiva e (iii) aplicação industrial.

Esses três requisitos são os mesmos desde a assinatura da Convenção da União de Paris em 1883, do qual o Brasil é um dos países signatários. Ou seja, esses três critérios são observados e harmonizados por diversos países. Ainda, o recente acordo TRIPS, vigente no Brasil desde 1994 cujo objetivo é o de harmonizar padrões mínimos de proteção à propriedade intelectual em diversos países do mundo - dispõe em seu art. 27.1 que "qualquer invenção, de produto ou de processo, em todos os segmentos tecnológicos, será patenteável, desde que seja nova, envolva um passo inventivo e seja passível de aplicação industrial”, o que mostra que referida convenção internacional em nada difere dos critérios adotados pela nossa legislação.

Entretanto, referido dispositivo deixa claro que os requisitos para a concessão de patentes devem ser iguais para todos os setores tecnológicos, inclusive o farmacêutico. Sendo a lei de propriedade industrial (9.279/96) promulgada dois anos após a entrada em vigor daquele tratado no nosso ordenamento jurídico, não deveria ser adicionado um quarto requisito à concessão de patentes no setor farmacêutico no País, qual seja, a anuência prévia da ANVISA, o que fere aquele Tratado.

\subsection{Diagnósticos relacionados à inovação brasileira}

A FAPESP, através de seu diretor científico Carlos Henrique de Brito Cruz também ressalta a importância da "desmistificação" da colaboração entre universidade e empresa, de que aquela deve ser um apêndice desta (FAPESP, 2008). A universidade deve ser dedicada ao progresso do conhecimento para que ela continue a gerar conhecimento relevante para a sociedade, e não apenas para contribuir com as empresas. Assim, um dos aspectos que poderiam ajudar a universidade e 
institutos de pesquisa a cumprir esse papel seria posicioná-la de forma mais robusta no que diz respeito à cadeia de inovação, principalmente em relação aos direitos sobre a propriedade intelectual de suas criações.

O que dizer, então, de seus pesquisadores, cujo empenho no desenvolvimento de inovações, normalmente, não recebe uma contrapartida financeira proporcional ao esforço empreendido? Não teriam eles também interesse em licenciá-las a quem queira oferecer uma real recompensa a tais esforços?

Por certo a proteção à propriedade intelectual, como já demonstrado, talvez seja o maior entrave para as empresas não investirem em inovação biotecnológica e farmacêutica no País, na proporção que deveriam para aumentar e solidificar a excelência de seus produtos que as próprias características naturais do Brasil (biodiversidade) e a qualidade de suas pesquisas podem proporcionar. Robert Sherwood, consultor e pesquisador internacional da área de transferência e comercialização de tecnologia e um dos especialistas internacionais consultados pela FAPESP para a elaboração da "Lei de Inovação" brasileira, ao mencionar a necessidade de alguns ajustes técnicos na lei para seu aprimoramento, frisa que esta dá mais importância aos investimentos estatais do que o fomento por meio do investimento privado (CASTRO, 2008). Ora, se as empresas não investem por questões relacionadas a lacunas nas regras de proteção à propriedade intelectual, a equação da questão permanecerá de difícil solução.

No Brasil é importante atentar para tais aspectos vez que, apesar de certos avanços, podermos considerar que o País, nos campos da biotecnologia e farmacêutico tem grande potencial. E, nesses setores, os avanços na pesquisa universitária irão afetar diretamente, e de forma mais significativa, a inovação industrial, mais até que em outros, como demonstram estudos feitos nos Estados Unidos sobre o tema (MOWERY et al, [ca. 2003]). 


\section{OBJETIVOS}

Considerando o arcabouço jurídico brasileiro relacionado ao direito à propriedade intelectual, exploramos as alternativas nele existentes que, por um lado, assegurem esse direito aos investidores públicos e privados, e, por outro, aos pesquisadores/inventores. Em outras palavras, buscamos no referido arcabouço os meios legais para tornar seguros os investimentos e tornar possíveis as inovações nas áreas biotecnológica e farmacêutica. 


\section{MATERIAIS E MÉTODOS}

O material a ser utilizado na pesquisa refere-se à legislação brasileira que rege a questão da inovação e assuntos correlatos, dentre outros, a Lei 10.973/04, o Decreto 5.563/05, a Lei 9.279/96. As questões referentes à titularidade de patentes são regidas pela lei 9.279/96 que, em seu art. $6^{\circ}$, afirma:

Art. $6^{\circ}$ Ao autor de invenção ou modelo de utilidade será assegurado o direito de obter a patente que lhe garanta a propriedade, nas condições estabelecidas nesta Lei.

$\S 1^{\circ}$ Salvo prova em contrário, presume-se o requerente legitimado a obter a patente.

$\S 2^{\circ}$ A patente poderá ser requerida em nome próprio, pelos herdeiros ou sucessores do autor, pelo cessionário ou por aquele a quem a lei ou o contrato de trabalho ou de prestação de serviços determinar que pertença a titularidade.

$\S 3^{\circ}$ Quando se tratar de invenção ou de modelo de utilidade realizado conjuntamente por duas ou mais pessoas, a patente poderá ser requerida por todas ou qualquer delas, mediante nomeação e qualificação das demais, para ressalva dos respectivos direitos.

$\S 4^{\circ} \mathrm{O}$ inventor será nomeado e qualificado, podendo requerer a não divulgação de sua nomeação.

O assunto também é tratado pelos artigos 88 a 93 da lei, abaixo transcritos:

Art. 88. A invenção e o modelo de utilidade pertencem exclusivamente ao empregador quando decorrerem de contrato de trabalho cuja execução ocorra no Brasil e que tenha por objeto a pesquisa ou a atividade inventiva, ou resulte esta da natureza dos serviços para os quais foi o empregado contratado.

$\S 1^{\circ}$ Salvo expressa disposição contratual em contrário, a retribuição pelo trabalho a que se refere este artigo limita-se ao salário ajustado.

$\S 2^{\circ}$ Salvo prova em contrário, consideram-se desenvolvidos na vigência do contrato a invenção ou o modelo de utilidade, cuja patente seja requerida pelo empregado até 1 (um) ano após a extinção do vínculo empregatício.

Art. 89. O empregador, titular da patente, poderá conceder ao empregado, autor de invento ou aperfeiçoamento, participação nos ganhos econômicos resultantes da exploração da patente, mediante negociação com o interessado ou conforme disposto em norma da empresa.

Parágrafo único. A participação referida neste artigo não se incorpora, a qualquer título, ao salário do empregado.

Art. 90. Pertencerá exclusivamente ao empregado a invenção ou o modelo de utilidade por ele desenvolvido, desde que desvinculado do contrato de trabalho e não decorrente da utilização de recursos, meios, dados, materiais, instalações ou equipamentos do empregador. 
Art. 91. A propriedade de invenção ou de modelo de utilidade será comum, em partes iguais, quando resultar da contribuição pessoal do empregado e de recursos, dados, meios, materiais, instalações ou equipamentos do empregador, ressalvada expressa disposição contratual em contrário.

$\S 1^{\circ}$ Sendo mais de um empregado, a parte que lhes couber será dividida igualmente entre todos, salvo ajuste em contrário.

$\S 2^{\circ}$ É garantido ao empregador o direito exclusivo de licença de exploração e assegurada ao empregado a justa remuneração.

$\S 3^{\circ}$ A exploração do objeto da patente, na falta de acordo, deverá ser iniciada pelo empregador dentro do prazo de 1 (um) ano, contado da data de sua concessão, sob pena de passar à exclusiva propriedade do empregado a titularidade da patente, ressalvadas as hipóteses de falta de exploração por razões legítimas.

$\S 4^{\circ}$ No caso de cessão, qualquer dos co-titulares, em igualdade de condições, poderá exercer o direito de preferência.

Art. 92. O disposto nos artigos anteriores aplica-se, no que couber, às relações entre o trabalhador autônomo ou o estagiário e a empresa contratante e entre empresas contratantes e contratadas.

Art. 93. Aplica-se o disposto neste Capítulo, no que couber, às entidades da Administração Pública, direta, indireta e fundacional, federal, estadual ou municipal.

Parágrafo único. Na hipótese do art. 88, será assegurada ao inventor, na forma e condições previstas no estatuto ou regimento interno da entidade a que se refere este artigo, premiação de parcela no valor das vantagens auferidas com o pedido ou com a patente, a título de incentivo.

No que concerne à participação do funcionário público - independente de ser ou não titular de alguma patente em co-titularidade com qualquer outra entidade - além do parágrafo único do art. 93 acima, a norma do art. $3^{\circ}$. do Decreto 2553/98, também deve ser mencionada:

Art. $3^{\circ}$ Ao servidor da Administração Pública direta, indireta e fundacional, que desenvolver invenção, aperfeiçoamento ou modelo de utilidade e desenho industrial, será assegurada, a título de incentivo, durante toda a vigência da patente ou do registro, premiação de parcela do valor das vantagens auferidas pelo órgão ou entidade com a exploração da patente ou do registro.

Ainda, a lei federal de inovação (10.973/04), regulamentada pelo Decreto 5.563/05, trata da questão da participação e da titularidade dos pesquisadores públicos no resultado das invenções de forma "passiva”, deixando ambos os tópicos sob responsabilidade das partes contratantes, como mostra o art. $9^{\circ}$, par. $2^{\circ}$. e o art. 13 , abaixo transcritos:

Art. 9ํㅡ É facultado à ICT celebrar acordos de parceria para realização de atividades conjuntas de pesquisa científica e tecnológica e desenvolvimento de tecnologia, produto ou processo, com instituições públicas e privadas. 
$\S 2^{0}$ As partes deverão prever, em contrato, a titularidade da propriedade intelectual e a participação nos resultados da exploração das criações resultantes da parceria, assegurando aos signatários o direito ao licenciamento, observado o disposto nos $\S \S 4^{0}$ e $5^{\circ}$ do art. $6^{0}$ desta Lei.

Art. 13. É assegurada ao criador participação mínima de 5\% (cinco por cento) e máxima de 1/3 (um terço) nos ganhos econômicos, auferidos pela ICT, resultantes de contratos de transferência de tecnologia e de licenciamento para outorga de direito de uso ou de exploração de criação protegida da qual tenha sido o inventor, obtentor ou autor, aplicandose, no que couber, o disposto no parágrafo único do art. 93 da Lei $n^{\circ} 9.279$, de 1996. (grifamos)

Além dessas, é importante ressaltar que o Código Civil Brasileiro é utilizado como fonte subsidiária para confirmar a legitimidade de cada co-titular em explorar sua invenção, como no artigo abaixo:

Art. 1.314 - Cada condômino pode usar da coisa conforme sua destinação, sobre ela exercer todos os direitos compatíveis com a indivisão, reivindicá-la de terceiro, defender sua posse e alhear a respectiva parte ideal, ou gravá-la.

Como material de pesquisa será utilizado também o "Contrato de Cooperação Científica e Tecnológica e Autorização de Licenciamento de Exploração de Patentes“ firmado em Dezembro de 2004 entre a FAPESP e o Consórcio de Indústrias Farmacêuticas (COINFAR), parceiros industriais do CAT, tendo como interveniente o Prof. Antonio Carlos Martins de Camargo, coordenador do CAT. Por este contrato, o COINFAR teria o direito de explorar economicamente o resultado das pesquisas do CAT que resultaram em patentes, através de licenças específicas concedidas pelos cotitulares de cada uma, mediante o pagamento de royalties aos licenciantes.

O Bayh-Dole Act, promulgado nos Estados Unidos em 1980, será utilizado como exemplo de uma estratégia governamental para o incentivo da inovação gerada pelo setor acadêmico.

A metodologia utilizada envolve a análise jurídica dos entraves gerados como conseqüência da assinatura do "Contrato de Cooperação Científica e Tecnológica e Autorização de Licenciamento de Exploração de Patentes”. A legislação vigente à época da assinatura do contrato, bem como a atual são consultadas, assim como o Bayh-Dole Act para a formulação de sugestões que possam resultar no fortalecimento da inovação nas áreas farmacêutica e biotecnológica. 


\section{RESULTADOS E DISCUSSÃO}

Tomando como ponto de partida o referido "Contrato de Cooperação Científica e Tecnológica e Autorização de Licenciamento de Exploração de Patentes” assinado em 01 de Dezembro de 2004, identificamos os seguintes aspectos que serão analisados com mais detalhes:

a. Por este contrato o COINFAR teria o direito de explorar economicamente o resultado das pesquisas do CAT, que resultaram em patentes, através de licenças específicas concedidas pelos cotitulares de cada uma, mediante o pagamento de royalties aos licenciantes.

b. Os pedidos de patente tinham entre seus co-titulares não só a FAPESP como também pesquisadores lotados no Instituto Butantan, e que estavam trabalhando nas pesquisas desenvolvidas pelo CAT.

Contudo, transcorrido determinado período do início da relação, aquele esforço em conjunto para desenvolver novos medicamentos com base nas pesquisas do CAT caiu por terra, vez que o COINFAR optou por tentar excluir da titularidade das patentes a ele licenciadas alguns dos pesquisadores do Instituto Butantan, tentando convencê-los a transferir ao referido instituto a sua parte na titularidade das patentes, inclusive notificando extrajudicialmente alguns pesquisadores.

Todavia, a pretensão do COINFAR não encontra respaldo na legislação específica, pois à época que os pedidos de patente foram depositados no INPI a titularidade dos mesmos foi acordada entre as partes requerentes. Além disso, mesmo que fosse intenção do Instituto Butantan em figurar como titular de tais patentes, isso não seria possível pelo fato de não ter personalidade jurídica própria.

Apesar dessa tentativa, vale lembrar que referido contrato - do qual o termo outorgado ao responsável pelo CAT é parte integrante - assinado pelo COINFAR e FAPESP, reconhece que a equipe de pesquisadores do CAT tem parte na titularidade dos pedidos de patente depositados no INPI (cláusula $1^{\mathrm{a}}$.) e que os depósitos, de fato, foram todos requeridos em co-titularidade entre (i) uma das empresas do COINFAR, (ii) a FAPESP e (iii) um dos pesquisadores aderentes ao programa CAT-CEPID (cláusula $5^{\mathrm{a}}$.). Além disso, o contrato estabelece o pagamento de royalties à FAPESP e aos pesquisadores (cláusula $7^{\mathrm{a}}$.). 
Em reportagem recente, veiculada no jornal A Folha de São Paulo, edição de 26.12.2008, no caderno “Ciência e Saúde”, intitulada "Lei afasta inventor da posse de patentes” (GERAQUE, 2008), na qual é feita menção direta ao caso do CAT ora estudado, um dos representantes do COINFAR afirma que "numa instituição de pesquisa, a patente pertence à instituição. Não ao pesquisador”. Essa afirmação causa estranheza, pois foi feita decorridos quatro anos da assinatura do contrato pelo COINFAR. Além disso, já ficou demonstrada a possibilidade de uma instituição, por contrato, permitir que um pesquisador seja co-titular de um pedido de patente. No caso da FAPESP, o “Termo de Outorga e Aceitação de Auxílio” deixou isso claro (notamos que, na versão das “Condições Gerais de Concessão de Benefícios” desse mesmo termo na versão do ano de 1999 ou seja, já na vigência da atual lei de propriedade industrial que rege a matéria e vigente no ano anterior ao da outorga dos benefícios ao responsável pelo CAT - a redação do item XIV era: “Fica estabelecido que, caso a pesquisa objeto deste Termo resulte em invento patenteável, os direitos daí decorrentes, assim como seus resultados econômicos, serão compartilhados, pela metade, com a FAPESP”. Salientamos que referidos direitos incluem a titularidade das patentes. Ainda, o item XV estabelecia: "Fica certo também que, na hipótese da cláusula anterior, o registro de eventual patente, obrigatório prioritariamente no Brasil, se fará sempre em nome da FAPESP e do OUTORGADO, cabendo a qualquer deles a iniciativa do requerimento, dando ciência à outra parte”. Claro está, portanto, a anuência da FAPESP quanto à participação do pesquisador na titularidade das patentes).

É fato que as indústrias podem sentir-se incomodadas com a divisão da titularidade de patentes com pesquisadores, principalmente por força das operações de licenciamento. Apesar disso, a presença dos mesmos no caso aqui relatado nada tem de irregular, pois está em conformidade com a legislação supracitada, como já demonstrado.

Por outro lado, o arcabouço legal brasileiro que rege a questão da co-titularidade da propriedade intelectual (patentes) em relação à sua exploração carece de uma regulação uniforme. O Código Civil Brasileiro, como mencionado, contém uma previsão geral sobre condomínios (cotitularidade voluntária). Entretanto, regras específicas sobre propriedade intelectual devem prevalecer sobre previsões gerais. Também a lei 9.279/96, como demonstrado, prevê a existência da co-titularidade em matéria de patentes de maneira genérica, sendo importante ressaltar, também, as regras especiais para reger a co-titularidade existente por força de relação empregatícia, aplicada, também, à Administração Pública, direta e indireta (art.91). 
Apesar de o Código Civil dispor sobre a legitimidade que cada co-titular tem para explorar legitimamente sua invenção, tal mandamento não envolve atos de disponibilidade como nos casos de licenciamentos, que necessitam da concordância unânime dos demais co-titulares. Nos casos em que a co-titularidade é dividida entre um empregador e um empregado, tem aquele direito exclusivo a licenciar a invenção, pagando a este uma justa remuneração.

Já a lei de inovação também não institui nenhum dispositivo determinante em relação à titularidade de patentes. Apenas deixa transparecer, como já explicado, que isso será tratado por contrato entre as Partes. (citamos a participação do pesquisador/inventor em ganhos econômicos auferidos por ICT resultante de contratos de transferência de tecnologia e licenciamento para outorga de direito de uso da criação de que tenha sido inventor como exemplo).

Todavia, nesse mesmo arcabouço, vislumbramos hipóteses que podem ser consideradas satisfatórias se “enxertadas” por outros dispositivos/figuras jurídicas para permitir a expansão das atividades de pesquisa de forma mais recompensadora para os pesquisadores e institutos de pesquisa.

\subsection{Sociedades de Propósito Específico (SPE)}

Um dos exemplos encontra-se no artigo $5^{\circ}$ da Lei da Inovação, que permite à União e suas entidades autorizadas a participar - minoritariamente - do capital de empresa privada de propósito específico que vise ao desenvolvimento de projetos científicos ou tecnológicos para a obtenção de produtos ou processos inovadores. Nesse caso, o resultado sobre a propriedade intelectual gerada pertencerá às instituições na proporção de suas participações.

Uma “sociedade de propósito específico - SPE” tem por objetivo desenvolver algo que seja lícito, mas que, pelo fato de não ser um novo tipo societário, deverá estar organizada sob uma forma capaz de lhe acrescer personalidade jurídica (como, por exemplo, uma sociedade anônima ou sociedade limitada), e ter prazo limitado.

O que desperta a atenção nessa figura jurídica é (i) esse tipo de sociedade deve ser firmada entre o Estado e um particular, (ii) de forma distinta de uma "sociedade de economia mista”, seu 
controle fica na mão do particular vez que a participação societária deste é sempre maior do que a do Estado.

Ora, sendo constituída uma estrutura legal com essas características para a elaboração de pesquisas e desenvolvimento, a preocupação com a proporção da participação nos resultados sobre a propriedade intelectual gerada já está definida na própria lei de inovação (art. $5^{\circ}$, par. $1^{\circ}$.).

Assim, entendemos que esse tipo de estrutura para desenvolvimento de "P\&D" seria muito útil dentro do que hoje é disponibilizado pelo conjunto de leis que tratam do assunto no Brasil. Devemos somar a isso o fato da lei de inovação (art. 15) permitir ao pesquisador público obter uma licença para constituir empresa (por um período máximo de seis anos) cujo escopo seja a inovação.

Sendo assim, somos da opinião que o pesquisador - seja sob a forma de pessoa natural, seja sob a forma de quotista ou acionista de sociedade - pode, em conjunto com um instituto de pesquisa ou com uma Universidade, constituir uma SPE para tal propósito. Conseqüentemente, pela própria estrutura dessa sociedade, teria o pesquisador a maioria do capital social e, por conseguinte, maior parte nos rendimentos dos resultados nas invenções.

Assumindo isso, outros aspectos importantes teriam que ser delineados. O primeiro é a questão da titularidade das invenções. Sendo uma patente, como dito, um bem móvel, por óbvio é de interesse do inventor (e titular) dela dispor sob todos os aspectos permitidos pela lei e também, em muitos casos, transferi-la a seus sucessores em caso de seu falecimento.

A equação para a solução desses problemas seria a utilização de um acordo - dependendo da estrutura societária escolhida, poderia ser um “Acordo de Acionistas” ou “Acordo de Quotistas” no qual seriam estabelecidas as condições complementares ao Estatuto (ou Contrato Social, dependendo da estrutura), onde seriam deslindadas, dentre outras questões, (i) a co-titularidade nas patentes da sociedade, (ii) a forma de dissolução da sociedade (como demonstrado, ela será por prazo determinado), (iii) o destino das patentes antes de “cair em domínio público” e após o término da sociedade, (iv) os critérios para licenciamento e cessão das invenções, o que incluiria o perfil das entidades que seriam licenciadas. 


\subsection{Instituições Científicas e Tecnológicas (ICT)}

Outro assunto que merece atenção é a questão de institutos de pesquisa que, por qualquer motivo, o que inclui suas características organizacionais, ainda não constituam uma ICT, como é o caso do Instituto Butantan em São Paulo. Tomando esse exemplo, notamos que referido instituto não tem personalidade jurídica, vez que subordinado à "Coordenação dos Institutos de Pesquisa da Secretaria da Saúde” e criado por Decreto (ROSEMBERG, 2007), não podendo, por isso, ser titular de nenhum direito de propriedade intelectual.

Esse entendimento, na visão do próprio Instituto, causa um grande impasse na questão. O Dr. Otávio Azevedo Mercadante reconhece que o Instituto não tem um núcleo de inovação tecnológica e cogita a hipótese de sua fundação ser o agente do Butantan nas questões envolvendo titularidade e licenciamento de patentes. Mas, afirma, por não ter pesquisadores, que aquela fundação não pode ser uma ICT e, por isso, não poderá usufruir das benesses da lei de inovação (MERCADANTE, 2008).

Não obstante, foi aprovada em São Paulo a Lei Complementar no. 1049 (lei complementar é aquela que tem por objetivo acrescentar algo à Constituição), conhecida como a "lei paulista de inovação", mas que ainda não está em vigor. Por essa lei foi criada a figura da "Instituição Científica e Tecnológica do Estado de São Paulo” (ICTESP), que vem a ser um órgão ou entidade da administração pública estadual direta ou indireta que tenha por missão institucional executar atividades ligadas à inovação tecnológica, à pesquisa científica e tecnológica e ao desenvolvimento tecnológico, dentre outros. As ICTESPs poderão desenvolver projetos de inovação com instituições públicas e privadas sendo que as criações que resultem dos projetos desenvolvidos reger-se-ão em consonância com a legislação federal, o que significa a incidência dos ditames da lei no. 9.279/96, dentre outros dispositivos, sobre aquelas.

A “lei paulista de inovação”, tal qual a lei federal de inovação, facultará as ICTESPs a celebrar contratos de transferência de tecnologia e de licenciamento para outorga de uso ou de exploração de criação protegida, após a oitiva dos núcleos de inovação tecnológica (NIT) que as integram.

É importante salientar que o ato normativo 135/97 do INPI, define os contratos que impliquem transferência de tecnologia como sendo os de licença de direitos (exploração de patentes 
e de desenho industrial e uso de marcas) e os de aquisição de conhecimentos tecnológicos (fornecimento de tecnologia e prestação de serviços de assistência técnica e científica), e os contratos de franquia. Isso significa que, de acordo com a referida lei, o licenciamento de patentes por uma ICTESP, após o cumprimento de suas formalidades internas, será permitido. Assim, após a constituição de seu NIT, o Instituto Butantan poderá licenciar patentes que tenha desenvolvido em parceria com outras instituições, observando suas diretrizes internas em relação aos principais tópicos que envolvam os licenciamentos, como, por exemplo, a titularidade das patentes. Tais diretrizes foram estabelecidas por meio da portaria TBD - 7 de 4.4.2008, pela qual referido instituto constituiu uma comissão de inovação tecnológica (CIT) que tem, dentre seus objetivos, implementar diretrizes para análise relativa à possibilidade de patenteamento de invenções e identificar casos em que haja interesse em firmar contratos de transferência de tecnologia.

Por outro lado, é importante salientar que o Instituto Butantan, após cumpridas as formalidades da lei estadual de inovação, poderá, de fato, licenciar as invenções que tenham sido desenvolvidas ou em parcerias com outras instituições ou internamente, mas não poderá cedê-las (vendê-las), por ser vedado pelo art. 272 da Constituição Estadual de São Paulo. Por aquele dispositivo, o patrimônio científico dos institutos e centros de pesquisa da administração direta, indireta e fundacional são inalienáveis e intransferíveis, sem audiência da comunidade científica e aprovação prévia do Poder Legislativo.

Assim, é recomendável que institutos que se encontram na mesma situação do Butantan sejam transformados em "Instituições Científicas e Tecnológicas - ICTs” para encontrar guarida na própria lei de inovação. Para tanto, é obrigatória a constituição de um "Núcleo de Inovação Tecnológica - NIT”, que poderia ser próprio ou compartilhado com outra ICT com o objetivo de gerir sua política de inovação.

\subsection{Licenciamento de Invenções de Propriedade do Estado}

Outra sugestão que poderia gerar um estímulo maior no setor privado para fortalecer o crescimento da inovação no País seria a utilização de um mecanismo semelhante ao utilizado na legislação americana aqui comentada como paradigma de sucesso, o Bayh Dole Act. 
De acordo com aquela legislação, uma agência federal poderá conceder uma licença exclusiva, parcialmente exclusiva ou não exclusiva para patentes de titularidade do Estado, preferencialmente, para empresas de pequeno porte, mas que tenham as mesmas (ou melhores) condições de produzir produtos derivados de tais patentes do que uma empresa de maior parte. Além disso, a preferência para o licenciamento com essas características será para empresas daquele País.

Se o Brasil adotar esse tipo de procedimento em relação ao licenciamento de patentes detidas por seus entes públicos nesses segmentos, somos da opinião de que poderá haver um crescimento no número de empresas de biotecnologia, que normalmente são empreendimentos de pequeno porte, mas com grande capital intelectual agregado (daí o seu grande valor).

Citamos novamente como exemplo a possibilidade dada pela lei de inovação federal (art. 15) para o pesquisador público se afastar do órgão em que está lotado (licença) para constituir empresa com a finalidade de desenvolver atividade empresarial relativa à inovação. Se novas empresas de biotecnologia "nascerem" da iniciativa de pesquisadores, isso por certo poderia despertar o interesse de grandes indústrias farmacêuticas para operações de licenciamento. Até porque a constituição de uma empresa limitada, no Brasil, é algo barato e rápido. 


\section{CONCLUSÃo}

Pela análise da legislação que rege os aspectos legais da participação dos pesquisadores públicos na co-titularidade das patentes no Brasil, claro está que isso é legítimo. Não obstante, têm as instituições públicas às quais esses pesquisadores são vinculados a legitimidade para, por seus Estatutos Internos, vedar ou permitir a participação dos mesmos na co-titularidade do resultado das invenções das quais participam.

No que diz respeito específico ao Estado de São Paulo, independente da incidência dessas regras, a Constituição Estadual - no art. 272 - estabelece que o patrimônio científico dos institutos e centros de pesquisa da administração direta, indireta e fundacional são inalienáveis e intransferíveis sem audiência da comunidade científica e aprovação prévia do Poder Legislativo. Assim, independente da presença do Estado na co-titularidade de patentes obtidas conjuntamente com o setor privado poder ser considerado um fator de dificuldade para o desenvolvimento da inovação nesses segmentos, entendemos que a interpretação dessa norma legal autoriza o licenciamento de patentes que tem o Estado como co-titular (o que fica mais certo ainda se analisarmos o texto da lei estadual da inovação acima citada). Entretanto, os particulares que são co-titulares dessas patentes, apesar de proprietários do bem, não poderão cedê-los (vendê-los) se o Poder Legislativo não anuir com a operação. Isso encontra respaldo no "Princípio da Supremacia do Interesse Público”, um dos pilares de nosso direito administrativo, segundo o qual sempre que houver conflito entre um particular e um interesse público coletivo, deverá o interesse público prevalecer. E isso é bastante claro se mencionarmos, por exemplo, a co-titularidade de uma empresa privada e o Estado na patente de um medicamento que possa levar à cura de uma doença letal. É improvável que o interesse privado se sobreponha ao público.

Por tais motivos, a presença do Estado na co-titularidade de patentes desenvolvidas com boa parte dos recursos - seja financeiro, administrativo ou humano - fornecidos pelo setor privado, pode, como de fato vem acontecendo, afastar investimentos maiores em pesquisa na área biomédica por empresas particulares. 


\section{REFERÊNCIAS BIBLIOGRÁFICAS}

CAMARGO, A. C. M.; SCIVOLETTO, R.; D"AVILA, S. G. Sinergia entre a indústria e os cientistas brasileiros para a inovação farmacêutica. In: MDIC. (Org.). Futuro da Indústria de Fármacos. [s.l]: MDIC, 2004, v. 1.

CASTRO, F.. Inovação desprotegida. Agência FAPESP, São Paulo, 25 jun. 2008. Disponível em: $<$ http://www.agencia.fapesp.br/materia/9028/entrevistas/inovacao-desprotegida.htm>. Acesso em: 10 set. 2008.

CAT-CEPID. Research, Innovation and Dissemination. Relatório 2007. Disponível em: $<$ http://cat-cepid.tempsite.ws/relatorios/2007/relatorio2007.htm>.

COORDENAÇÃO DE APERFEIÇOAMENTO DE PESSOAL DE NÍVEL SUPERIOR. 2007. Disponível em: <HTTP:// www.capes.gov.br>. Acesso em: 15 set. 2008.

COUNCIL ON GOVERNMENTAL RELATIONS. The Bayh-Dole Act guide to the law and implementing regulations. California : University of California, 1999. Disponível em:

$<$ http://www.ucop.edu/ott/faculty/bayh.html>.

GERAQUE, E. Lei afasta inventor da posse de patentes. A Folha de São Paulo, São Paulo, 26 dez.2008. Caderno Ciência e Saúde.

KJELDGAARD, R. H. Pharmaceutical and Biotechnology Patent Law in the United States. CATCEPID. São Paulo : [s.n], 2001. 120 p.

LOUREIRO, L. G. A.V. A lei de Propriedade Industrial Comentada. São Paulo : Lejus, 1999. 40 p.

MARQUES, F. Competitividade: lição dos inovadores. FAPESP, São Paulo, n.147, maio. 2008. Disponível em: <http://www.revistapesquisa.fapesp.br/?art=3514\&bd=1\&pg=1>.

MERCADANTE, Otávio Azevedo. Instituto Butantan: orçamento de R\$ 130 milhões para P\&D em saúde. InovaBrasil. (Entrevista). Disponível em:

$<$ http://inovabrasil.blogspot.com/2008/03/instituto-butantan-oramento-de-r-130.html>.

Acesso em: 25 mar. 2008.

MIRANDA, M. A. T. Vamos Nacionalizar a Indústria Farmacêutica? Rio de Janeiro : Civilização Brasileira, 1963. Cadernos do Povo Brasileiro, $n^{\circ}$ 11. p. 20, 21; 52-56.

MOWERY, D. C., SAMPAT, B. N. The Bayh-Dole Act of 1980 and University-Industry

Technology Transfer: A Model for Other OECD Governments? - Artigo científico sobre pesquisa conduzida pelos professores Richard Nelson da Universidade de Columbia e Arvids Ziedonis da Universidade de Michigan. Disponível em:

$<$ http://siepr.stanford.edu/programs/SST_Seminars/HBSemulationtalk.pdf>. Acesso em: 18 out. 2008. 
ROBEN P. Enterprise Ireland's unique public-private approach to getting research into business. TheScientist. Disponível em: <http://www.the-scientist.com/2008/07/01/s26/1/>. Acesso em: 26 out. 2008.

ROSEMBERG, B. Parecer datado de 10 de Setembro de 2007, encomendado pela FAPESP referente à análise de questões ligadas às patentes desenvolvidas com base em pesquisas realizadas naquele instituto.

SOCIEDADE BRASILEIRA PRÓ-INOVAÇÃO TECNOLÓGICA. Cópia criativa reflete a realidade da indústria farmacêutica nacional. Notícias Protec. - Disponível em: <http://www.protec.org.br/noticias_inovacao_patente.asp?cod=177>. Acesso em: 28 nov. 2008. 